\begin{tabular}{c|c|c}
\hline \hline & CLIMATE RESEARCH \\
Vol. 24: 103-117, 2003 & Clim Res & Published July 28 \\
\hline
\end{tabular}

\title{
Tornado hazards in the United States
}

\author{
Bryan J. Boruff, Jaime A. Easoz, Steve D. Jones, Heather R. Landry, \\ Jamie D. Mitchem, Susan L. Cutter*
}

Department of Geography, University of South Carolina, Columbia, South Carolina 29208, USA

\begin{abstract}
Losses from all natural hazards have increased steadily over the past 3 decades and a continuous cycle of Presidential disaster declarations was generated as communities rebuilt and recovered from these often devastating events. Using a $50 \mathrm{yr}$ record, this paper examines the temporal variability and spatial distribution of tornado hazards in the United States. Tornado hazards are defined very specifically as any reported tornado that resulted in human injury, human fatality, or some amount of economic loss. The results suggest that, while the actual number of tornadoes (tornado segments) doubled over the entire time period, there was a smaller overall increase in the number of tornado hazards from 1950 to 2000. The ratio of tornado hazards to all tornadoes has remained relatively constant since the 1960s. There has been a steady decline in fatalities and reductions in injuries caused by tornado hazards. Losses are more variable over the past $50 \mathrm{yr}$, but the 1990s showed near record lows, in terms of both total dollar losses and mean losses per tornado hazard event. The statistical center of tornado hazard activity is in south-central Missouri, southeast of the statistical center of tornadoes identified by previous research. The density of tornado hazards has expanded outward from the historic 'Tornado Alley' region. The distribution of other high-density regions suggests additional tornado hazard regions in Florida, the lower Mississippi Valley, the Gulf Coast, and in the Carolinas.
\end{abstract}

KEY WORDS: Tornado hazards · GIS · Spatial variation $\cdot$ Temporal trends

\section{INTRODUCTION}

Natural hazards and disasters have been common occurrences throughout American history. In the US, natural hazards accounted for more than $\$ 300$ billion in damages, 9000 fatalities, and over 73000 injuries in 1975-1998 (Cutter 2001). Annual losses averaged more than $\$ 12.5$ billion during this same time period. Fortunately, fatalities and injuries have decreased in recent decades (Platt 1999), but crop and property damages from all hazards continue to escalate (Changnon \& Changnon 1999, Mileti 1999). In the past $20 \mathrm{yr}$, for example, there were 46 different billiondollar weather disasters in the US, with a total estimated loss of $\$ 277$ billion. The majority of these occurred in the 1990s, resulting in $\$ 145$ billion in losses for the decade alone (National Climatic Data Center, NCDC, 2002). If billion-dollar earthquake events in the last $20 \mathrm{yr}$ also are included (e.g. Loma Prieta and Northridge, CA), another $\$ 8$ billion can be added to the total. There is no doubt that in the future natural hazards will cause even more destruction of property, as population densities and property values rise, and hazard mitigation policies remain static, especially in many high-risk areas.

Among the different natural hazards, flooding caused the most fatalities and the largest losses during the past $25 \mathrm{yr}$ (Cutter 2001). In comparison to other hazard events during this same time period, tornadoes caused the third highest number of fatalities, after floods and lightning. Based on damage totals, tornadoes also ranked third in total dollar losses, right behind floods and hurricanes.

This paper examines the spatial and temporal changes in the tornado hazard within the US in order to discover shifts in the relative level of hazardousness 
from these natural events. Three questions guide our analysis: (1) Are tornado hazards more frequent now than in the past? (2) Has the tornado hazard shifted geographically during the past $50 \mathrm{yr}$ ? (3) What specific regions have seen an increase in tornado hazards during the past half-century?

\section{DEFINING TORNADO HAZARDS}

In our usage, tornado hazard has a very distinctive meaning, and clearly should not be confused with tornado climatology. Tornado hazard encompasses some aspects of tornado climatology, but also includes the effect of these events on people and the built environment. While numerous studies on tornado climatology have examined tornado frequencies (Schaefer et al. 1980, Grazulis 1993, Golden 1999), to date there is no comprehensive analysis of both tornadoes and their social impacts on a national scale. We define the tornado hazard as any tornado that results in a human fatality, or a human injury, or any amount of reported economic damage. We are guided in this approach by the natural-hazards literature, which defines a natural hazard as the interaction between physical systems and human-use systems that produces a 'loss' (White \& Haas 1975, Burton et al. 1993). If a tornado occurs and is reported, but there is no recorded human injury, fatality, or economic loss, then it does not adhere to our definition of a tornado hazard.

There are 3 important elements embodied within the definition of a hazard according to the hazard-research community (Mileti 1999, Cutter 2001). The first is the risk or the likelihood of the hazard happening and having some adverse impact. The second element is exposure or a measure of the people or property that are subject to a given risk. The third element is vulnerability (susceptibility to harm), which emphasizes the ability of people and the environment to recover from the impacts of a hazard.

We make the assumption that deaths, injuries, and property damages caused by tornadoes have always been reported, although many non-hazard tornadoes probably have not been reported. Thus, changes in the distribution of the tornado hazard potentially are influenced more by shifting demographic patterns and increases in societal vulnerability rather than advancements in detection and reporting systems for tornadoes and the damage they produce. It is important to illustrate the geographic variability of tornado hazards, which we expected to differ from tornado frequency (in the strict climatological context), in order to determine whether these hazards have increased over time and across regions.

\section{UNDERSTANDING THE HUMAN ECOLOGY OF TORNADO HAZARDS}

The greatest loss of life from tornadoes in the 20th century occurred in 1925, with more than 800 fatalities, three-quarters of them from the Tri-State tornado outbreak of that year. According to Grazulis (2001), tornado outbreaks are defined as more than 6 tornadoes produced from a single weather system with no break in tornado activity lasting for $6 \mathrm{~h}$ or more. The 1925 Tri-State event affected Missouri, Illinois and Indiana, and produced one of the longest continuous single tornado tracks ever recorded (Galway 1981). The second highest yearly death toll was in 1936, with 551 deaths, again with more than three-quarters of them in 1 outbreak (Tupelo-Gainesville, MS). In 1953, tornadoes killed 519 people, the highest yearly total in the past half-century (Storm Prediction Center 2002). In recent years, 3 different tornado outbreaks each caused more than $\$ 1$ billion in damages: Arkansas-Tennessee in 1999, Oklahoma-Kansas in 1999, and Midwest-Ohio Valley in 2001 (NCDC 2002). For example, in January 1999, 2 outbreaks of tornadoes over a $6 \mathrm{~d}$ period struck Arkansas and Tennessee, causing 17 deaths and approximately $\$ 1.3$ billion in damage. Presidential disaster declarations were made for 55 counties, which provided some federal assistance and relief in the clean up and recovery (NCDC 2002).

Normally, tornadoes are localized phenomena associated with thunderstorms, but they also occur during hurricanes making landfall. Although atmospheric processes are critical in understanding tornado climatology, they do not fully explain or help identify the geographic or temporal variability in tornado touchdowns (Monmonier 1997, 1999). Often, the tremendous damage and destruction wrought by tornadoes is perceived as a local issue. Yet, in 3 separate ratings of the 20th century's top 10 US weather and climate events (Accuweather 1999, Henson et al. 1999, NOAA 1999), 2 were multi-state tornado outbreaks - the Tristate tornado outbreak in 1925 and the Super tornado outbreak in 1974. Whether local or regional in scale, the catastrophic potential of tornadoes is apparent.

\subsection{Establishing the tornado risk}

The most exhaustive study of US tornado risk is by Grazulis $(1993,2001)$. Using a 45 yr record, he identified a primary risk region in the Great Plains stretching from the Texas Panhandle northward through central Oklahoma and Kansas to Nebraska. A second area of concentration stretched northeast from south-central Mississippi to northern Alabama. Smaller 'tornado 
alleys' were also found in eastern Iowa, south-central Indiana, western Pennsylvania, and central Arkansas. Similarly, Schaefer et al. (1993) found the typical Great Plains concentrations, but other notable clusters in Mississippi, Alabama, and Georgia.

The number of reported tornadoes has increased significantly in past decades and is generally explained by advancements in observation, reporting, and documentation (Bluestein 1999, Golden \& Adams 2000). While the overall number of tornado occurrences has increased during the past $100 \mathrm{yr}$, the number of tornadoes rated as F2 or greater (on the Fujita-Pearson intensity scale) has not (Grazulis 2001). Schaefer et al. (1993) acknowledged the influence of geographic factors on designating certain areas within the US as prone to strong and violent tornadoes (F2 and greater), such as central Oklahoma, and they argued that these risk areas were more reflective of population density, not necessarily tornado occurrences of F2 or greater. However, the most severe tornadoes (F4 or F5) caused a disproportionate number of fatalities $(53 \%$ between 1985 and 1993) despite their rarity (less than $1 \%$ of all tornadoes recorded; Lillibridge 1997).

Sims \& Bauman (1972) compared diurnal tornado activity between 5 northern states and 5 southern states, and found no significant regional differences in the timing or in the frequency of the more violent storms. They did find that the average path length of tornadoes occurring in the South was shorter than those occurring in northern states, a finding later confirmed by Changnon \& Changnon (1999, p. 287).

\subsection{Population exposure: deaths, injuries, and property damage}

The American Meteorological Society (AMS) Council found that during the 1980s and 1990s the annual number of deaths declined to 55, half of what the fatality rate was during the period from 1950 to the 1970 s (AMS Council 2000). Property damage (based on data from 1975-1998 using standardized 1999 dollars) was less consistent, peaking in 1984 and showing annual variability before and after (Mitchell \& Thomas 2001).

Why have fatalities associated with tornadoes decreased during the past 5 decades, while property damage remains variable during this same time period? According to the AMS Council (2000), the most prominent factors that contributed to the decline in fatalities were improvements in detection and warning, an increase in public awareness, and improvements in the delivery of information, such as warning systems. For example, Sims \& Bauman (1972) found that the number of deaths caused by tornadoes was higher in the South than in the rest of the nation. They attributed the differential losses to the availability (or lack) of warning systems, as well as to differences in the type and quality of the housing stock. In a posttornado sample survey of the 1982 Marion, Illinois, tornado, Duclos \& Ing (1989) found that the overwhelming majority of the town's residents were aware of the tornado before it touched down. This awareness prompted actions such as seeking shelter, a precautionary measure that ultimately reduced the number of fatalities and injuries from that particular event.

In addition to improved warning systems, there are other factors that have helped to reduce human casualties from tornadoes. Improved sheltering of at-risk populations partially explains the decline in tornadorelated fatalities. For example, a number of studies showed that occupants of mobile homes suffered an increased risk of injury and death from tornadoes. Eidson et al. (1990) looked at the aftermath of a tornado outbreak in March 1984 in North and South Carolina. They found that $44 \%$ of the North Carolina fatalities and $51 \%$ of the North and South Carolina injuries happened to residents who lived in mobile homes. A Centers for Disease Control and Prevention study (CDC 1997) revealed the increased risk of mobile home residents and the importance of early warning systems and alternative shelters. This case study focused on a 1997 Arkansas tornado that struck a mobile-home park with 333 residents. A tornado warning was issued 15 to $18 \mathrm{~min}$ prior to the impact, giving residents time to flee the mobile-home park or to seek protection in the community shelter. More than half of the recorded fatalities occurred among people who did not leave or those who did not have access to underground storm shelters (CDC 1997). Similarly, in the 1991 Andover, Kansas (Butler County), tornado, no deaths or injuries were recorded among mobile-home park residents who left their homes or used a community shelter. Among the unsheltered population $(20 \%$ of the mobile home park's residents), $29 \%$ were killed and $45 \%$ were hospitalized (CDC 1992).

The structural characteristics of housing also influence the number of tornado fatalities and injuries. In the 1990 Plainfield, Illinois, tornado, which caused 29 deaths, occupants of 2-story homes were at greater risk of severe injury or death than people living in 1-story homes. New buildings were riskier than older homes, and occupants of brick homes had nearly twice as many severe injuries as residents living in wooden houses (Brenner \& Noji 1995). This was true whether residents were sheltered in basements or in interior rooms.

Another aspect of sheltering is the pattern in vehicleoccupant deaths resulting from tornadoes. Hammer \& Schmidlin (2000) examined the historic trends in vehicle mortality due to tornadoes, and they found that 
about $60 \%$ of the deaths occurred in F4 and F5 tornadoes, a pattern that is consistent with the overall record of tornado fatalities. Vehicle registrations have increased over the past $20 \mathrm{yr}$, yet vehicle occupant deaths have declined. Hammer \& Schmidlin (2000) suggest this is due to the increased safety features in cars, especially the use of seat belts. It also may be a function of increased preparedness and publiceducation efforts, both of which stress the fact that cars are not the most appropriate shelters or places to be during tornadoes.

Most fatalities and serious injuries caused by tornadoes are the result of the structural collapse of buildings, projectiles striking the victims, or the victims becoming airborne (Bohonos \& Hogan 1999). The availability of shelters and improved warning lead times are key factors in the overall decline in tornado deaths and injuries in the US (Golden 1997, Golden \& Adams 2000).

While injuries and fatalities have declined, property damage fluctuates both annually and by decade (Brooks \& Doswell 2001, 2002). This may be a function of several factors, including increasing populations, rising property values, demographic shifts, poorer construction practices, the nature of the housing stock (e.g. manufactured homes), better reporting and documentation, and better warning systems. For example, Changnon \& Changnon (1999) compared losses associated with weather disasters in the US during the 1990s with those from 1950-1989. Their results showed that the intensity of these disasters did not increase in the 1990 s, yet more weather events qualified as disasters. A recent increase in the number of damaging weather events also was observed along the West Coast and in the Southwest, particularly in areas with rapid increases in population, property values, and urbanization (Changnon \& Changnon 1999).

\subsection{Locational vulnerability}

Some hazard researchers view vulnerability as those conditions (susceptibility) that reduce the ability of people or places to respond to and recover from environmental threats, while others view vulnerability as the degree to which different social groups are at risk from hazards (Cutter 2001). There are macro- and micro-demographic trends that influence the differences in vulnerability to tornadoes in US (Sims \& Bauman 1972, Riebsame et al. 1986, Changnon \& Changnon 1999). Population growth, property density, and wealth have increased significantly in some regions during the past half-century, putting more lives and property at risk from severe weather events. Demographic shifts from the Northeast and Midwest to the South and eastern coastal areas amplified the hazard potential in these areas. For example, the highly vulnerable coastal counties stretching from Texas to North Carolina now contain $16 \%$ of the nation's population. Riebsame et al. (1986) noted similar demographic shifts to 'Sunbelt' states in the West and the South, which may have helped to increase the vulnerability of these areas to weather-related hazards. The depopulation of parts of the Great Plains helped to reduce that region's vulnerability to tornado hazards.

Another important demographic shift is the movement to urban areas. The percentage of the US population now living in metropolitan areas increased from $68 \%$ in 1970 to around $80 \%$ in 2000 (US Census Bureau 1997, 2001). This shift has led to greater population and building densities and potentially greater losses in these areas, even with respect to small-scale weather events. Although clustered populations are at a lower risk of experiencing a tornado event (Doswell et al. 1999), a study conducted by Aguirre et al. (1993) found that from 1950 to 1990 metropolitan counties had a higher occurrence of tornado disasters than rural counties. Aguirre et al. (1993) also found that central cities experienced fewer tornadoes than suburbs. Unfortunately, they merely speculated on explanations for the disparity, such as differences in terrain roughness and the presence of an urban heat island. The supporting climatological evidence is inconclusive on this point.

The tornado intensity classification system used in the US (the Fujita-Pearson scale) is based entirely on post-event damage assessments, which are derived from the wind speeds required to cause damage of given severities. There is an inherent population bias that influences how the intensity of a tornado is classified, a bias that is rarely acknowledged (Schaefer et al. 1993, Monmonier 1997, Golden 1999). Generally, less intense tornado events may result in greater damage in more densely populated areas, causing the event itself to be classified as a stronger storm than what the actual wind speeds would justify.

In summary, tornado climatology and tornado hazard research to date demonstrates: (1) the number of reported tornadoes increased rapidly during the past $50 \mathrm{yr}$, but the frequency of strong (F2 or higher) tornadoes remained relatively steady; (2) the observed increase in tornado frequency is due to better detection and reporting; and (3) weather changes were not the principal cause of tornado-related impacts on people and places.

Tornadoes continued to be a threat in those places that experienced them, but migration and increases in population density over time changed the geographical extent of the tornado hazard region. Many of these 
empirical analyses on tornado climatology and their impacts used varying time periods and different regions. To reconcile some of this variability in the temporal and geographic coverage of tornado hazards and to re-examine the findings from the literature, we investigated the historic and spatial pattern of tornado hazards during the past half-century.

\section{DEFINING AND MEASURING TORNADO HAZARDS}

The data used in this paper are from an archived tornado data set (1950-1999) maintained by the National Climatic Data Center at Asheville, North Carolina. The data set includes tornadoes for all US states, plus Puerto Rico, the US Virgin Islands, and Guam. Specific information on each tornado includes the longitude and latitude of touchdown, property and crop damages based on current dollars, numbers of fatalities and injuries, and Fujita-Pearson intensity. The tornado data were incorporated into a geographical information system (GIS) to create a digital map (shapefile) using the touchdown locations (longitude/latitude), which were then put into an Albers equal area projection for mapping and analytical purposes. Given the paucity of tornadoes in Alaska, Hawaii, Guam, Puerto Rico, and the Virgin Islands, as well as difficulties in density mapping, these states and territories were eliminated from the subsequent analyses.

The NCDC database includes both tornadoes and tornado segments. A tornado segment is that portion of the tornado's path within a single county. If the tornado crosses from one county to another, then 2 tornado segments are listed (Storm Prediction Center 2002). This means that the number of tornadoes in the NCDC database is inflated and does not represent tornadoes per se, but rather tornado tracks within counties. ${ }^{1}$ The corrected and verified NCDC database was modified further to include only tornado segments that resulted in any recorded impact measured as a death, an injury, or economic damage. Tornado segments that did not

\footnotetext{
${ }^{1}$ The tornado data set was derived from National Climatic Data Center's Storm Events Data Base, commonly referred to as Storm Data (run for 1950-2001). In our analysis, we only used the 1950-1999 data. The data were verified and spatially checked for correct county FIPS code. We corrected the tornado segments that were reported by climate zone or multiple counties, and we divided them among the respective counties. This increased the total number of segments for all decades with the exception of the 1990s. Finally, waterspouts, landspouts, gustnadoes, and all other non-tornado events were not included in our georeferenced database
}

meet these criteria were deleted. It should be noted that tornadoes could have caused an injury or death (which was recorded), but not have any reported economic damage. In this case, the particular tornado (or tornado segment) adheres to our definition and would be included in the tornado-hazards database. Cases with no economic damage but with a death or injury represent around $1.4 \%$ of the total.

There are also some caveats to the damage and casualty estimates. From 1950 to 1993, Storm Data only reported damages by loss category (1-9) based on a logarithmic scale (starting with Category 1 , at less than $\$ 50$, and ending with Category 9, ranging from $\$ 500$ million to $\$ 5$ billion). Since 1993, loss data have been reported in current dollars. On the 2001 digital version of Storm Data, NCDC computed dollar losses from 1950-1993 based on the midpoint of the logarithmic category. Reported crop losses were infrequently recorded prior to 1993, but were regularly reported thereafter. Finally, to facilitate comparisons over time, all damage values were standardized to 1999 dollars (Sahr 2001).

We fully recognize the shortcomings of the dollardamage and human-casualty data included in the NCDC data set (see Thomas 2001). While imperfect, these data do represent a conservative estimate of the human toll of tornado activity and comprise one of the better hazard-events and loss data sets.

\section{RESULTS AND DISCUSSION}

\subsection{Trends in hazard occurrences}

There were approximately 40522 reported tornadoes during the past 50 yr (1950-1999; Storm Prediction Center 2002). The number increased from the 1950 s to the 1970 s, decreased during the 1980s, and based on improved reporting and detection, increased by $48 \%$ in the 1990 s (Table 1 ).

The pattern of tornado hazards (those tornadoes that produced an injury, death, or dollar loss) shows a similar decadal trend. There is an increase in the number of tornado hazards from the 1950s to the 1970s, when it

Table 1. Frequency of tornado and tornado hazard events by decade. Tornado data from the Storm Prediction Center (2002). Tornado segments derived from the NCDC Storm Data CD and corrected for county accuracy by the research team

\begin{tabular}{|lccccr|}
\hline & $1950 \mathrm{~s}$ & $1960 \mathrm{~s}$ & $1970 \mathrm{~s}$ & $1980 \mathrm{~s}$ & $1990 \mathrm{~s}$ \\
\hline Tornadoes & 4796 & 6813 & 8579 & 8196 & 12138 \\
Tornado segments & 5227 & 7266 & 9361 & 8998 & 10262 \\
Tornado hazard events & 4323 & 5372 & 7137 & 6796 & 6016 \\
\hline
\end{tabular}



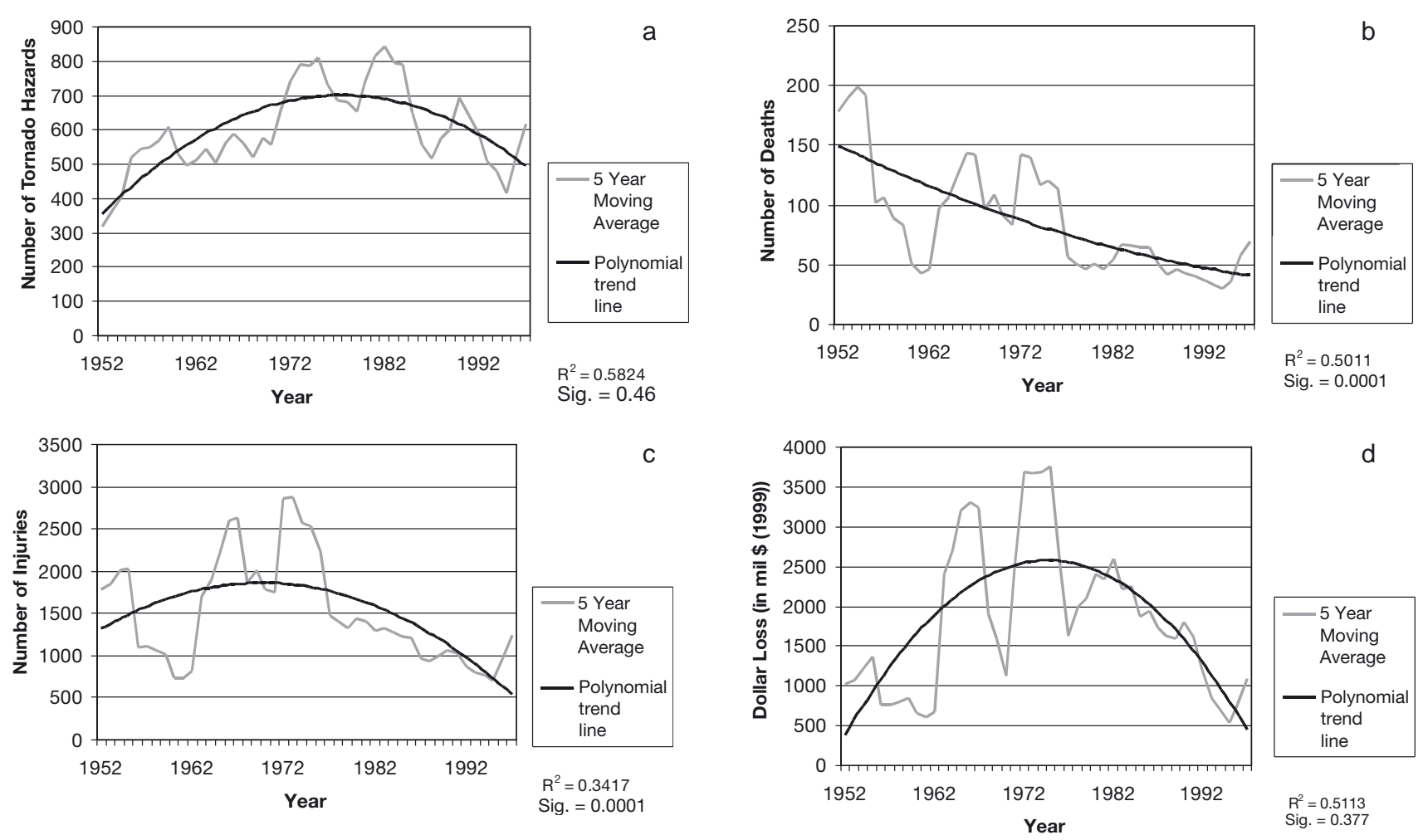

Fig. 1. Trends in tornado hazards in 1950-1999 based on a 5 yr moving average for (a) frequency, (b) fatalities, (c) injuries, and (d) dollar losses in millions standardized to 1999 dollars

peaked; a decline in the 1980s; and a continued decline in the 1990s (Table 1). During the 1950s, $82 \%$ of the tornado segments were classified as tornado hazards. Largely due to increased awareness, the following 3 decades saw a decline in the relative proportion of tornado hazards to overall tornadoes (segments), hovering between 74 and $76 \%$ from 1960 to 1989. During the 1990 s, the ratio of tornado hazards to tornado segments dropped to $58 \%$. The annual variability in the frequency of tornado hazards (depicted as a 5 yr moving average and a trend line based on a second-order polynominal function) shows an increase in tornado hazards until the mid-1970s followed by a slow decline (Fig. 1a).

When examining the decadal pattern of tornado injuries and fatalities, our analysis confirms the findings reported in the literature (Table 2). The decadal number of deaths has declined overall from 1950 to

Table 2. Casualties by decade

\begin{tabular}{|lrrrrr|}
\hline & $1950 \mathrm{~s}$ & $1960 \mathrm{~s}$ & $1970 \mathrm{~s}$ & $1980 \mathrm{~s}$ & $1990 \mathrm{~s}$ \\
\hline Injuries & 14470 & 17263 & 21636 & 11297 & 10564 \\
Fatalities & 1419 & 942 & 998 & 522 & 534 \\
\hline
\end{tabular}

2000, but there were 2 peaks in the annual trends (based on the 5 yr moving average): one in the mid1960s, and the other in the mid-to-late 1970s (Fig. 1b). The number of injuries increased each decade, starting in the 1950s, until it peaked in the 1970s, and then declined thereafter. Between the 1970s and the 1990s, there was a $51 \%$ reduction in the overall number of tornado injuries (Table 2). The annual variability (Fig. 1c) illustrates this, showing a peak in injuries in the mid-1960s and another peak in the mid-1970s. The overall trend (based on the second-order polynomial function) highlights the decline in injuries caused by tornadoes since the 1970 s.

Total economic losses (standardized to 1999 dollars) escalated from more than $\$ 9$ billion in the 1950s to more than $\$ 26$ billion in the 1970s. However, decadal losses declined to near record lows in the 1990s, in terms of both total losses as well as mean losses per event (Table 3). Minimum losses declined over the last half-century, as did maximum losses. The annual variability measured as the 5 yr moving average (Fig. 1d) shows 2 peaks in losses: one in the late 1960s and the other in the mid-to-late 1970s. There is a secondary rise in losses in the early 1980s based on the moving average, which is consistent with yearly raw data in showing more than $\$ 4$ billion total recorded damages 
Table 3. Dollar losses by decade (standardized to 1999 dollars)

\begin{tabular}{|lrrrrr|}
\hline & $1950 \mathrm{~s}$ & $1960 \mathrm{~s}$ & $1970 \mathrm{~s}$ & $1980 \mathrm{~s}$ & $1990 \mathrm{~s}$ \\
\hline Mean loss (\$ millions) & 2.16 & 3.65 & 3.73 & 3.18 & 1.91 \\
Minimum loss (\$) & 172 & 136 & 69 & 40 & 10 \\
Maximum loss (\$ millions) & 1562.50 & 1322.75 & 1077.59 & 507.10 & 450.00 \\
\hline
\end{tabular}

A slight southern shift in mean latitude of tornado hazards has occurred since 1950 (Fig. 3). While annual variability remains important, the polynomial trend lines show a small shift in mean latitude southward and a small shift in mean longitude eastward since 1950. But, when mapped by decade, the centroid of tornado hazards for all decades has not

in 1984 (Mitchell \& Thomas 2001). The trend in tornado hazard losses shows a classic parabolic curve, with losses steadily increasing from the 1950s to the 1960s, leveling off in the 1970s, and then declining thereafter. Despite the absolute increase in frequency of reported tornadoes and tornado county segments using decadal averages (Table 1), the relative proportion of tornado county segments that were classified as tornado hazards has remained relatively unchanged since the 1960s. In other words, two-thirds of all reported tornado segments resulted in an injury, death, or dollar loss during the past half-century.

\subsection{Geographic center of tornado hazard exposure}

In order to examine the geography of tornado hazards, the distribution of tornadoes (represented as touchdown points) was visually compared to a point distribution of tornado hazards for the same decade. This method provided little insight into which areas of the US were more prone to tornado hazards when compared to the incidence of tornadoes. In fact, for the entire time period and by specific decade, the only discernible difference between the distributions was a slight decrease in the overall density of points. Fig. 2 illustrates these patterns using the 1950s as an example.

The staff members of the National Severe Storms Forecast Center (NSSFC) were the first to conceive of and publish a map of the statistical center or centroid of tornado activity for the contiguous US (Schaefer et al. 1980). Using tornado data from 1950-1980, they located the center in south-central Missouri, near Grovespring. To assess the similarities and differences in the centroid location of all tornadoes versus tornado hazards, we computed the mean location (latitude and longitude) of tornado hazards per year and then averaged them for each decade as well as for the entire $50 \mathrm{yr}$ study period. ${ }^{2}$

\footnotetext{
${ }^{2}$ Working within the GIS, 2 fields are computed in the attribute tables of the shapefiles, one for the $x$-coordinate (touchdown point) and one for the $y$-coordinate (end of path) of the tornado hazards. After this, simple descriptive statistics were run to determine the mean value for each of these fields. Finally, yearly means were graphed and the decadal and 50 yr cumulative means were mapped
} moved out of south-central Missouri (Fig. 4). However, it should be noted that the centroid of tornado hazards is southeast of the statistical center of all tornado activity as identified in Schaefer et al. (1980). The average distance shifted ranged between 48 and 112 miles $(77-180 \mathrm{~km})$ of the 1950 s tornado hazards position, but this is not statistically significant given the large standard deviations of the decadal mean positions (Table 4). Decadal averaging, changes in tornado detection, random variation, or the fact that we only examined tornado hazards, not all tornadoes, may explain the statistical insignificance. The large standard deviation also may reflect geographic reality. Tornadoes are infrequent events west of the Rockies. The calculation of the mean centroid includes these spatial outliers, which could partially explain the large standard deviations resulting from this spatial interpolation of the data.

\subsection{Hazard density patterns}

Another way of illustrating the geography of tornado hazards is to focus on particular places or spatial units (for example, counties) in order to ascertain changes over time and space. The longitude and latitude of each tornado hazard segment were converted to frequencies per county, normalized using county area in square miles for each decade, and then mapped.

In the $1950 \mathrm{~s}$, the greatest tornado hazard densities by county were concentrated in the traditional 'Tornado Alley' in the Great Plains. There were some secondary concentrations in the counties bordering the Mississippi River, along the southern tip of Lake Michigan, in south Florida, and in central New England (Fig. 5a). A decade later, more high-density tornado hazard counties emerged along the Gulf Coast, extending from Texas to Florida. The southeast coast of Florida also showed a distinct concentration of tornado hazards during the 1960s (Fig. 5b). Another highdensity region, bordering on southern Lake Michigan, expanded southward during the decade as well.

In the 1970s, Florida and the Gulf Coast counties retained their high density of tornado hazards. This was also true of counties in the south-central region (especially eastern Oklahoma and Texas) and in counties bordering Lake Michigan and Lake Erie (Fig. 5c). 

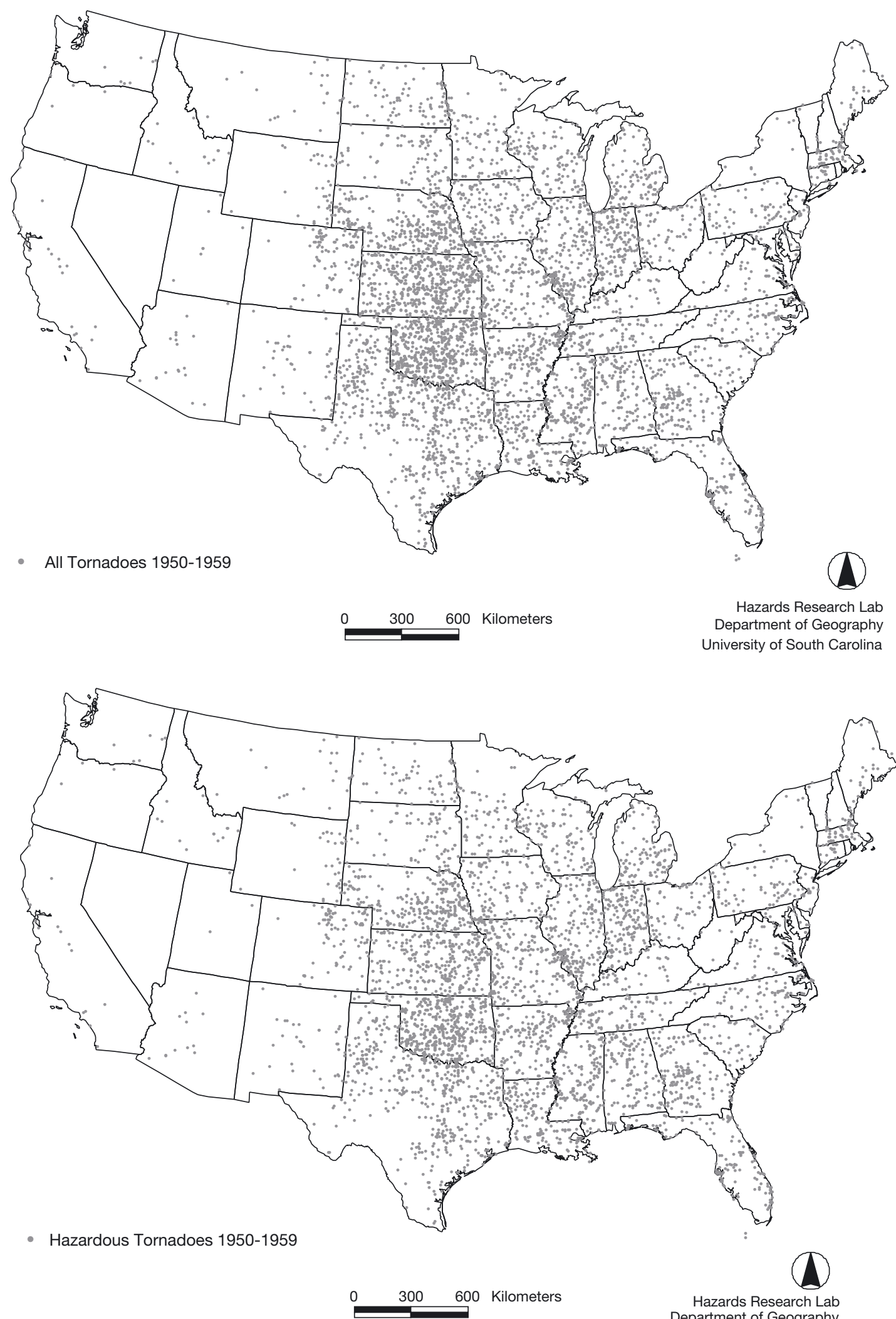

Hazards Research Lab University of South Carolina

b 


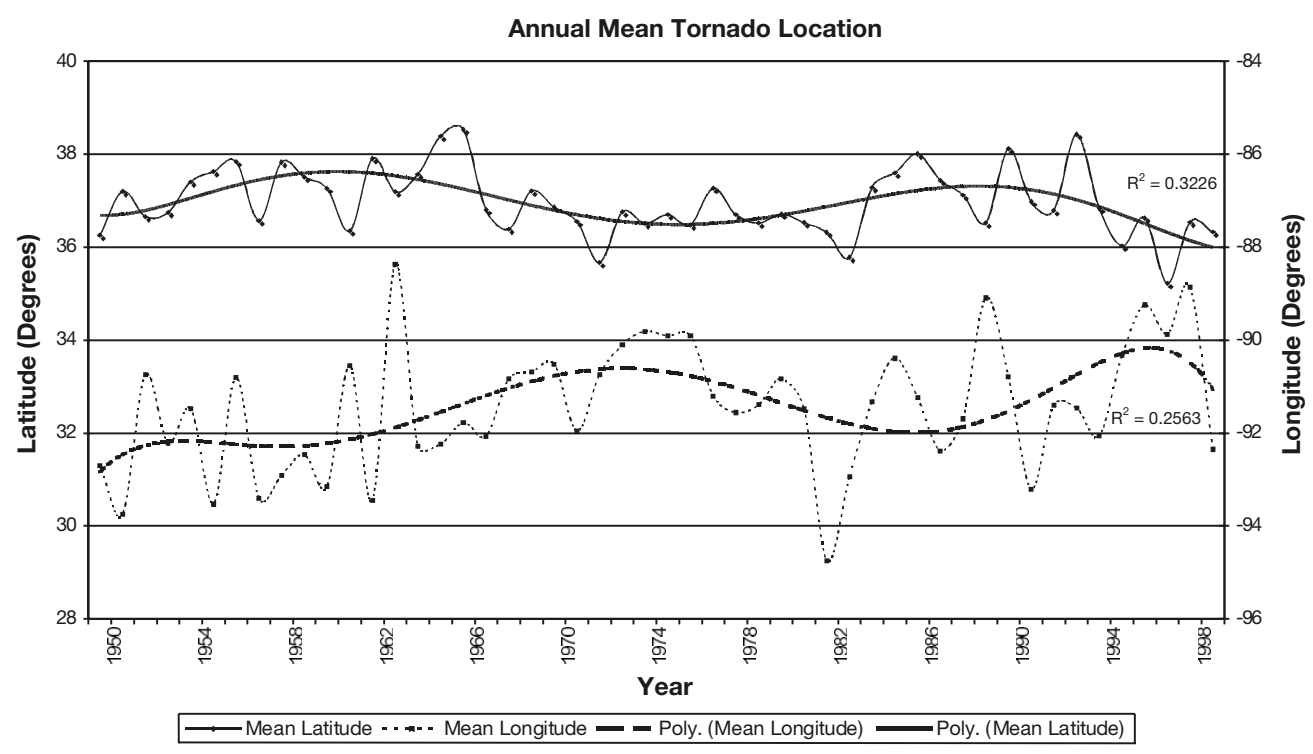

Fig. 3. Trends in longitudinal and latitudinal shifts in the annual statistical center of tornado hazard activity from 1950-1999

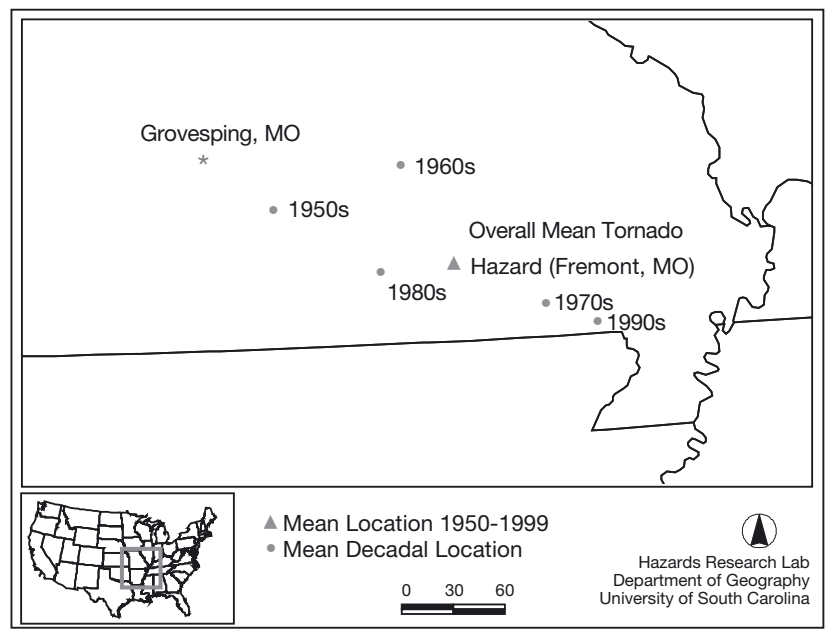

Fig. 4. Decadal means of tornado hazard centroids continue to be located in southeastern Missouri but have shifted slightly over time

During the 1980s, Florida remained an active place for tornado hazards, as did eastern Texas, Oklahoma, and Louisiana (Fig. 5d). Other high hazard counties were scattered throughout the upper Great Plains states. During this time period, a pattern of high density of events remained along the northern Gulf Coast. The increases in Florida from 1950 through the 1980s and in Arkansas in the 1980s are noteworthy.

The most striking hazard density pattern, however, occurs in the 1990s (Fig. 5e). This map shows high densities of tornado hazards in the Great Plains states stretching from coastal Texas to South Dakota, along the northern Gulf Coast, and over the entire state of
Florida. Other high hazard density areas include coastal counties along the mid-Atlantic region (especially in North Carolina and Virginia), in counties bordering the Chesapeake Bay, and in counties on the southwestern shore of Lake Erie (Fig. 5e). The geographic intensification of tornado hazards is clearly distinguishable from those of earlier time periods.

In order to monitor increases or decreases in hazard density values from one decade to another, county decadal changes were computed. The change maps showed similar geographic patterns to those described above. In examining changes in hazard density from the 1950s to the 1990s, those counties with hazard density increases are located in central New York, in Atlantic coastal states from Maryland and Delaware south to the Carolinas, in most of Florida, along the Gulf Coast, and in Iowa. Within the Great Plains region, the traditional 'Tornado Alley', there is considerable variability in changes in tornado hazard density, with some areas showing increases and others declines (Fig. 6a).

Table 4. Changes (mean $\pm \mathrm{SD}$ ) in decadal mean locations of tornado hazard events

\begin{tabular}{|lcc|}
\hline & Latitude $\left({ }^{\circ}\right)$ & Longitude $\left({ }^{\circ}\right)$ \\
\hline $1950 \mathrm{~s}$ & $37.20 \pm 4.55$ & $-92.40 \pm 7.93$ \\
$1960 \mathrm{~s}$ & $37.41 \pm 5.01$ & $-91.54 \pm 7.95$ \\
$1970 \mathrm{~s}$ & $36.65 \pm 5.11$ & $-90.63 \pm 7.96$ \\
$1980 \mathrm{~s}$ & $36.86 \pm 5.22$ & $-91.71 \pm 8.49$ \\
$1990 \mathrm{~s}$ & $36.54 \pm 4.86$ & $-90.30 \pm 8.06$ \\
\hline
\end{tabular}



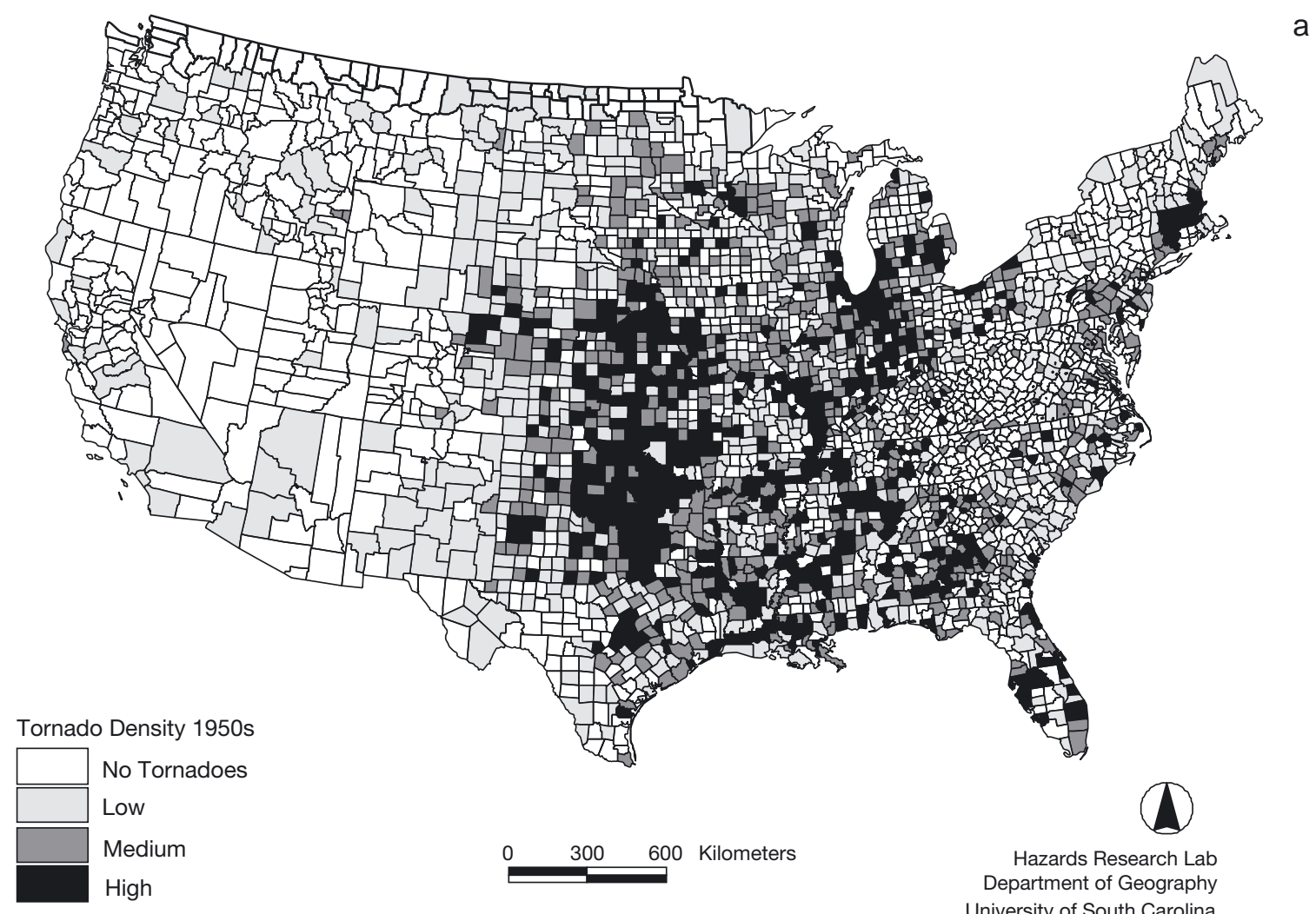

Tornado Density 1950s

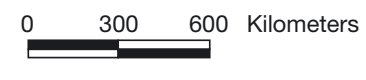

(1)

Hazards Research Lab Department of Geography University of South Carolina

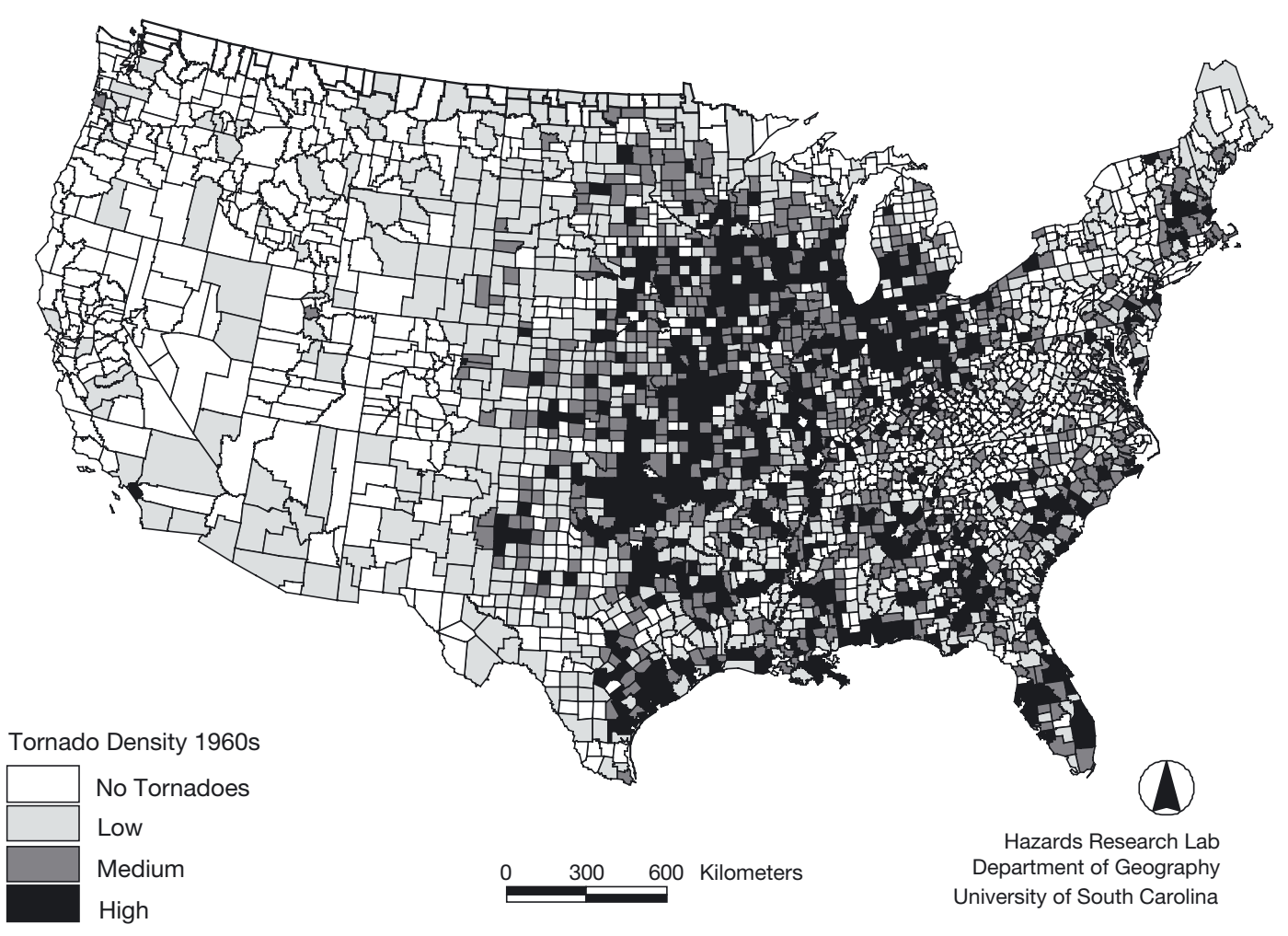

Fig. 5. (Above and following 2 pages.) Tornado hazards per county by decade, 1950-1999. The density of tornado hazards (frequency per square mile $\left[2.6 \mathrm{~km}^{2}\right]$ ) is mapped by county for the (a) $1950 \mathrm{~s}$, (b) $1960 \mathrm{~s}$, (c) $1970 \mathrm{~s}$, (d) $1980 \mathrm{~s}$, and (e) $1990 \mathrm{~s}$ 

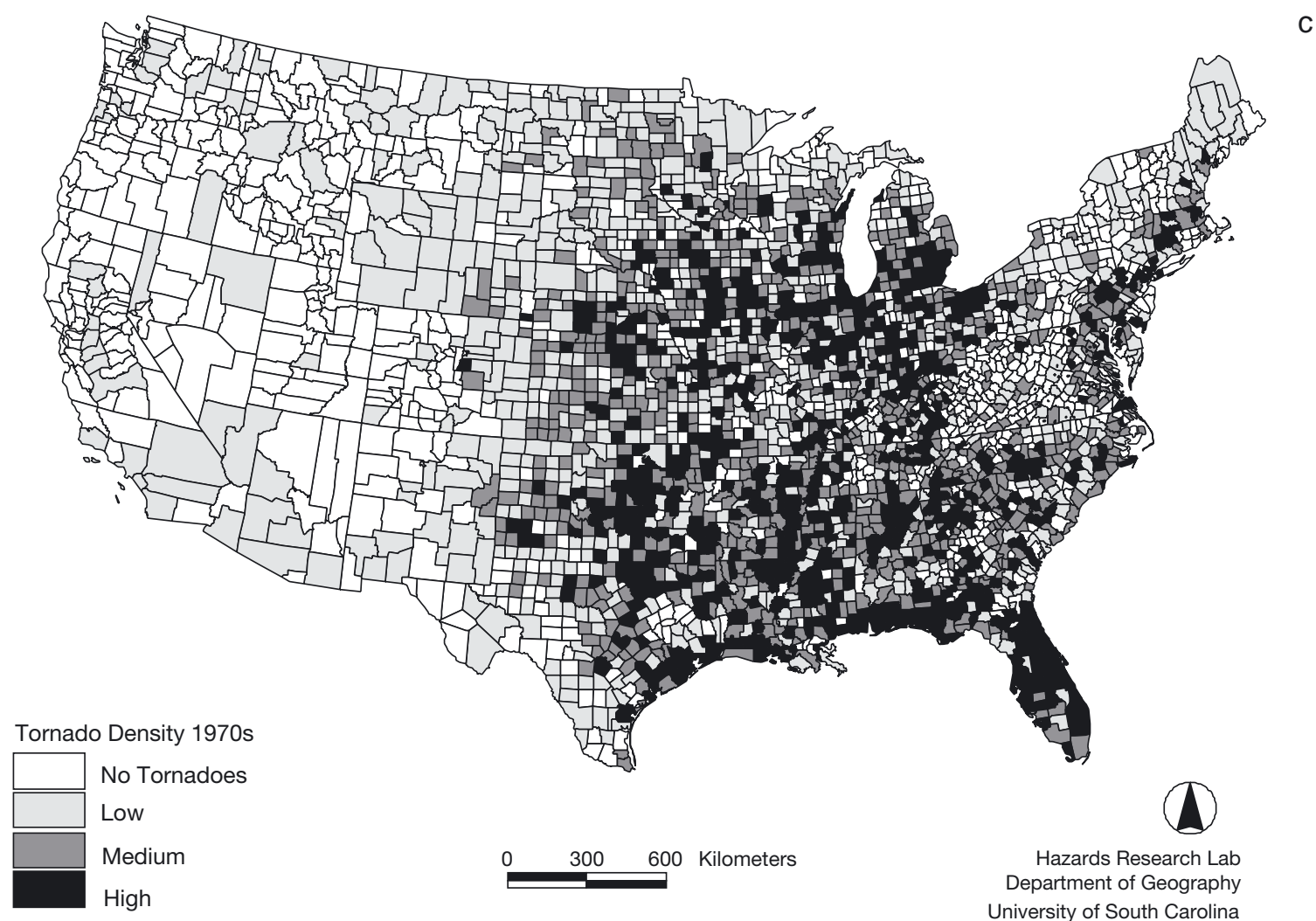

C
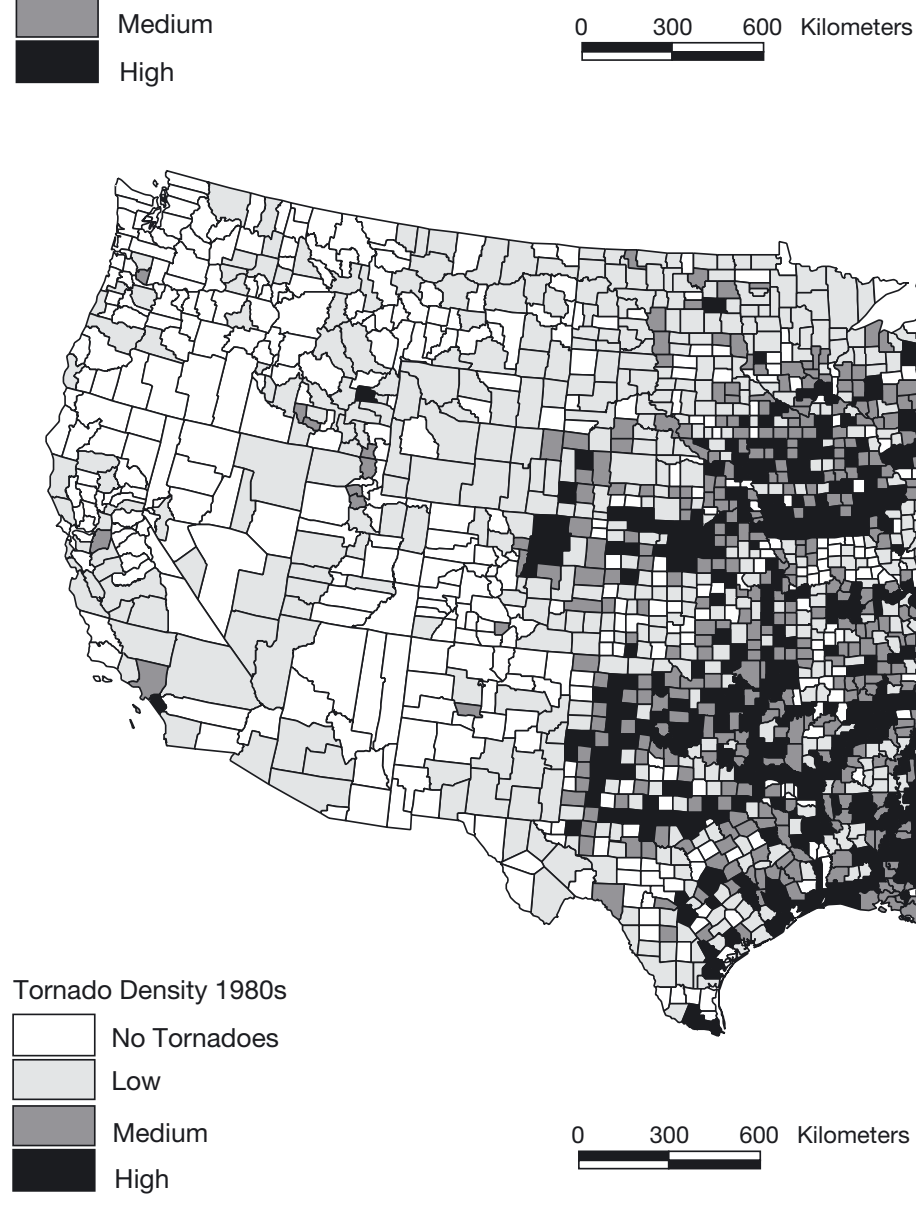

(1)

Hazards Research Lab Department of Geography University of South Carolina

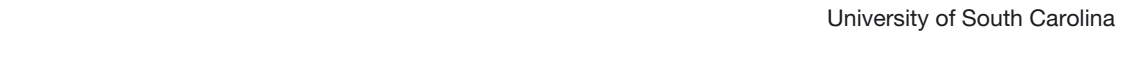




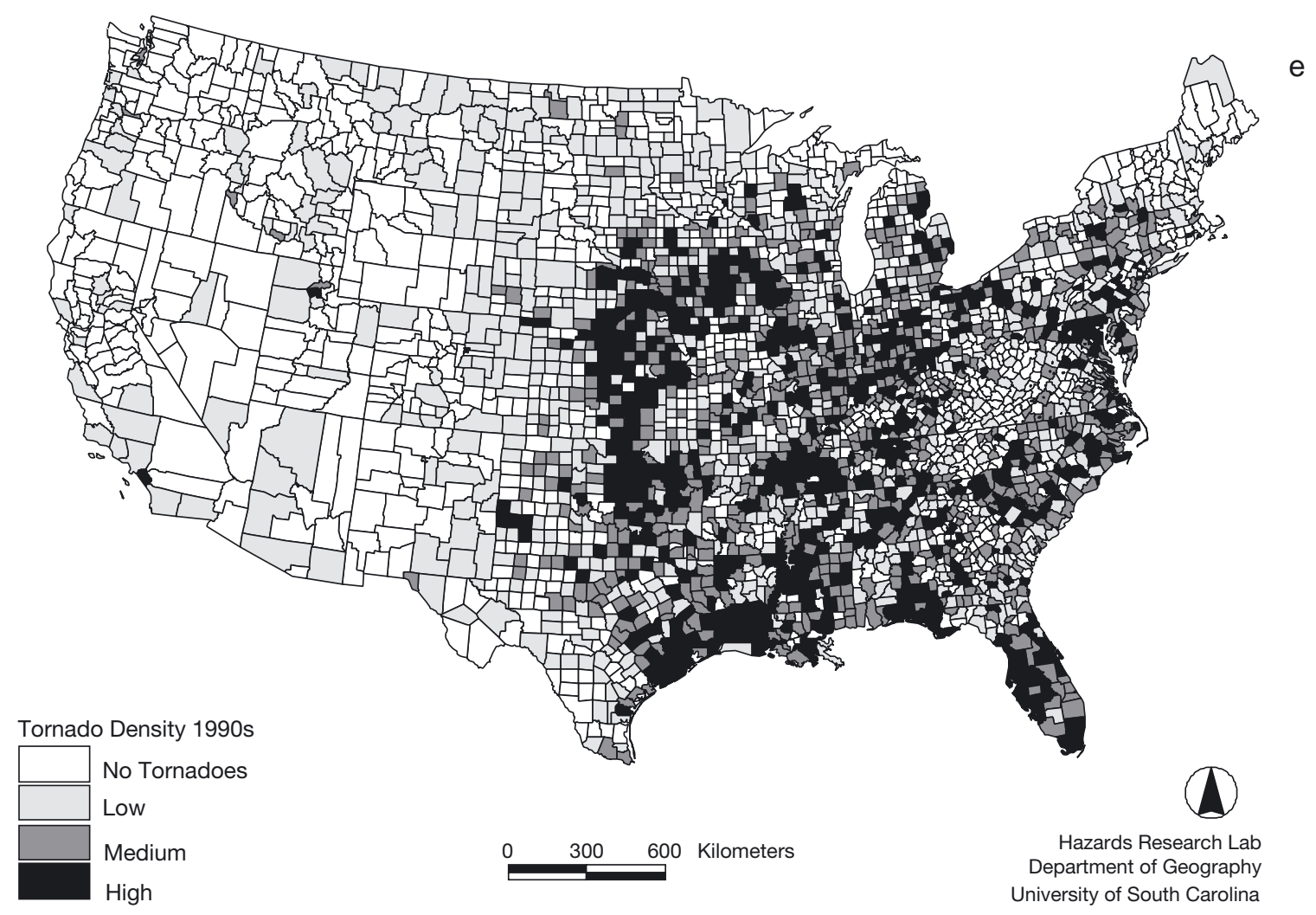

Fig. 5 (continued)

What accounts for such geographic patterns? To address this question, changes in population and population density were computed by county using 1950 and 2000 Census data, and then mapped. As shown in Fig. 6b, during the past half-century there has been a significant depopulation in the Great Plains, lower Mississippi Valley, and Appalachia regions. This depopulation partially explains some of the hazard density changes in selected counties and sub-regions. However, for the entire US there is little correlation between population density and tornado hazard density for any decade (Pearson's $r$ ranges from 0.013 to 0.067 with significance at $p=0.001$ ). This is partially explained by a statistical artifact due to the lack of tornado hazards ( $n=0$, so hazard density equals 0 as well) in many counties throughout the nation.

At least at the surface, it would appear that population and population density alone do not offer many explanations for the distribution of tornado hazards. But, population growth is a driving force behind rapid development of the built environment, and it is likely that development patterns are contributing to the increasing hazards. It is also likely that increases in the overall number of tornadoes in certain counties play a significant role as well. These factors certainly would explain the upsurge in tornado hazards in Florida and coastal counties from
North Carolina to Texas. In the Great Plains, the pattern is more complicated, suggesting an increase in the number of tornadoes, increased population (in some places), more urban and agricultural development, or some combination of all of these.

\section{CONCLUSION}

The frequency of tornadoes more than doubled during the latter half of the 20th century. It can be argued that some of the increase is climatological, but it is far more likely that it results from better tornado reporting as a result of heightened public awareness and improved detection technology. The frequency of tornado hazards (defined as tornadoes that resulted in injury, death, or economic loss to property or crops) shows a mixed trend consisting of increases from 1950 to 1979 , a decline in the $1980 \mathrm{~s}$, and an increase in the 1990s. However, the annual trend (based on a polynomial trend line fit to a $5 \mathrm{yr}$ moving average of hazard frequency) shows a steady decline since the 1980s. Damaging tornado events almost always were reported, thus reducing the non-reporting bias that may be prevalent in the tornado counts. Tornado deaths and injuries decreased over the past $50 \mathrm{yr}$ as a result of improved warning technology, such as the 

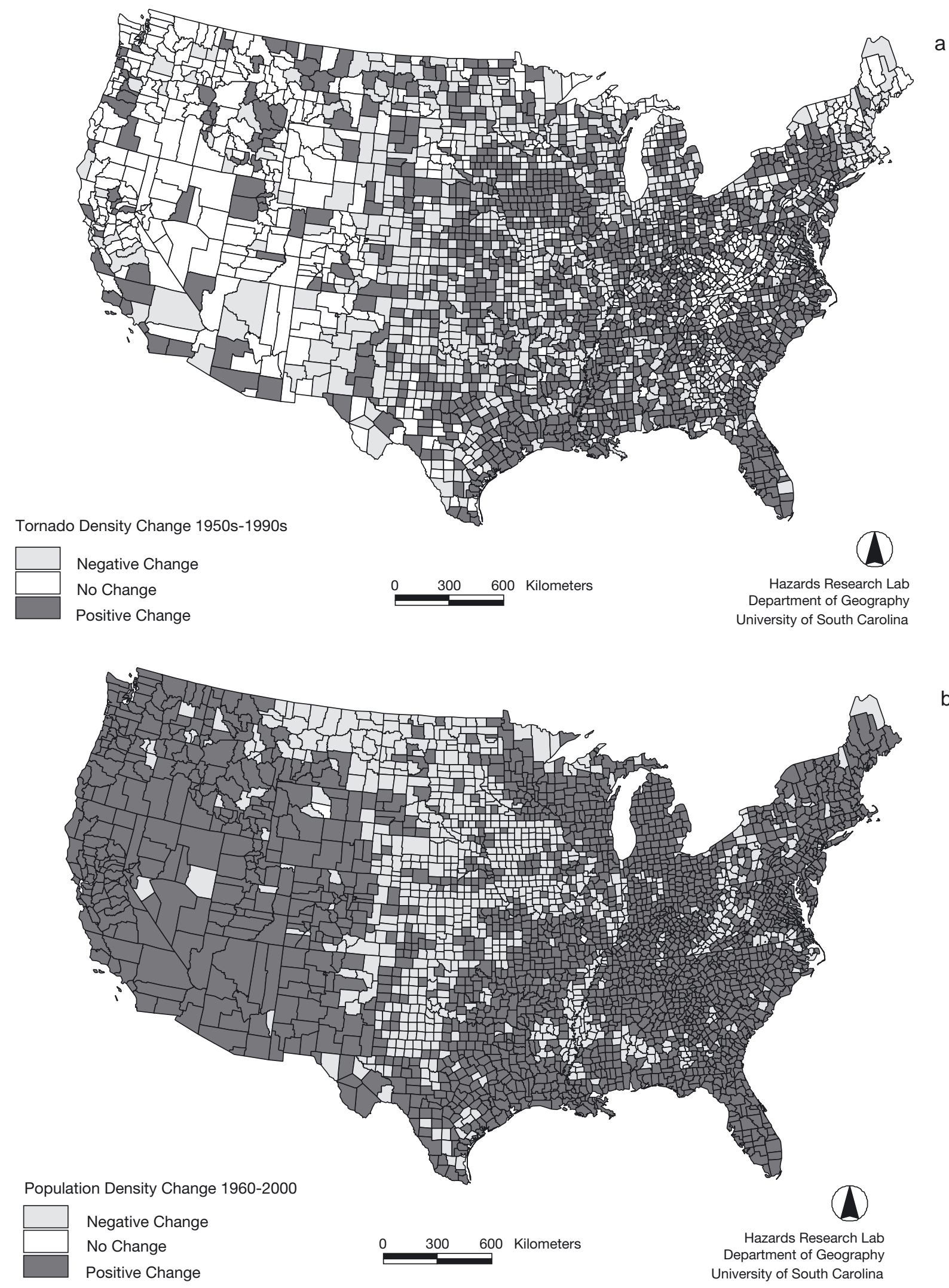

Fig. 6. Changes in tornado hazard and population density patterns 1950-1999. Positive changes in tornado hazard densities (a) are found in the Southeast, Florida, and along the Gulf Coast, while negative changes in population densities (b) are most visible in the western Great Plains and lower Mississippi Valley 
WSR-88D Doppler radar network, increased warning lead times, and improved public compliance with warnings. As expected, damage fluctuated wildly on an annual basis, with peaks in losses in the mid-1960s and mid-1970s. However, there was an upward trend (based on a $5 \mathrm{yr}$ moving average) in standardized dollar losses until the mid-1970s, and a steady decline thereafter.

Geographically, there was a slight shift in the statistical center of tornado hazards to the south and east of the 1950s mean centroid location. There are several probable reasons for this shift, including Sunbelt migration and consequent demographic changes, NWS (National Weather Service) tornado warning differences, and variations in public education and awareness.

Mapping the change in the density of tornado hazard events by county (frequency of tornado hazards per square mile) during the past $50 \mathrm{yr}$ showed that the regions with increases in hazard frequency were in the Midwest, Florida, the lower Mississippi Valley, the Carolinas, and the northern Gulf Coast. The juxtaposition of increasing population (and thus the increased potential for economic damage and human casualties) in regions susceptible to tornadoes contributed to the increased tornado hazards.

We focused our attention on those tornadoes that produced a loss, events that we labeled tornado hazards. There are a number of ways to expand the present analysis to offer fruitful areas for future research. For example, the distribution of high-density tornado hazard counties could be analyzed with respect to various socioeconomic indicators in order to determine the relationship between housing stock, income levels, and access to shelters - variables that might help to explain the spatial pattern of places with high or low tornado hazard densities. In this way, we could make an assessment of the social vulnerability of different regions to tornadoes. This information would be very useful for NWS and emergency management officials, who might want to target certain areas for increased public awareness and education campaigns or to implement advanced warning technology.

Other possibilities for future research include an examination of the spatial differences in tornado formation processes (e.g. hurricanes, cold fronts aloft, sea-breeze interactions, synoptic processes, and mesoscale processes). Along similar lines, it would be very instructive to develop models to study the impact of urbanization, land use, and topography on tornado formation and tornado hazard creation. This is another promising area of research, since urban populations are expanding, and urban tornado climatology is still in its infancy. Lastly, geographical regularities in tornado structure (e.g. multiple vortex, life cycle, anticyclonic rotation, outbreaks, and tornado families) may help us to understand the nature of the threat in various regions.

Another line of inquiry is to compare the US Presidential disaster declarations arising from tornadoes with those counties that actually had the most damage or casualties based on the present dataset. This comparison may indicate whether certain types of settlements (e.g. cities, rural communities) or specific states are preferred or ignored by the federal government's disaster assistance programs. Locational shifts in damage might be conducted to ascertain regional and temporal variability in high- and low-consequence events. Do major tornados (F3 or greater) cause the majority of economic losses or is it the cumulative impact of smaller, yet more frequent tornado hazards that produce the overall patterns shown here? This type of inquiry would help to differentiate the impacts of infrequent, yet higher-consequence (e.g. F4 or F5) tornado hazards, which often qualify for disaster relief, from a series of smaller, yet more frequent tornado hazards that do not meet the 'disaster declaration' threshold, despite the fact that their cumulative dollar loss impact over a period of time is just as great or greater than that caused by the singular event. These questions are beyond the scope of the present paper, but are important avenues for future tornado hazard research spanning both the social and natural sciences.

Acknowledgements. This paper is based on research supported by the National Science Foundation (CMS 9905352, S.L.C. and Dennis Mileti, Principal Investigators), for which we are most appreciative. The original ideas for the paper were developed in an advanced seminar in hazards research, but the data are part of the larger NSF work. We would like to thank Greg Carbone, Kirstin Dow, Michael Hodgson, Helen Power and the anonymous reviewers, who offered critical comments on the research and this manuscript. Cary Mock's advise and counsel was extremely helpful. Any errors of interpretation, omission, or commission, however, are ours.

\section{LITERATURE CITED}

Accuweather (1999) Top weather events of the century. Accuweather, State College, PA. Available at http:// www.accuweather.com/iwxpage/paws/news/991231top. htm

Aguirre BE, Saenz R, Edmiston J, Yang N, Agramonte E, Stuart DL (1993) The human ecology of tornadoes. Demography 30:623-633

AMS Council (2000) Tornado preparedness and safety. Bull Am Meteorol Soc 81:1061-1065

Bluestein HB (1999) Tornado alley: monster storms of the Great Plains. Oxford University Press, New York

Bohonos JJ, Hogan DE (1999) The medical impact of tornadoes in North America. J Emerg Med 17:67-73

Brenner SA, Noji EK (1995) Tornado injuries related to housing in the Plainfield Tornado. Int J Epidemiol 24:144-149 
Brooks HE, Doswell CA III (2001) Normalized damage from major tornadoes in the United States: 1890-1999. Weather Forecast 16:168-174

Brooks HE, Doswell CA III (2002) Deaths in the 3 May 1999 Oklahoma City tornado from a historical perspective. Weather Forecast 17:354-361

Burton I, Kates RW, White GF (1993) The environment as hazard, 2nd edn. Guilford Press, New York

Centers for Disease Control (CDC) (1992) Tornado disasterKansas 1991. Morbid Mortal Wkly Rep 41:181-183

Centers for Disease Control (CDC) (1997) Tornado associated fatalities-Arkansas 1997. J Am Med Assoc 278:279-280

Changnon SA, Changnon D (1999) Record-high losses for weather disasters in the United States during the 1990s: how excessive and why? Nat Hazards 18:287-300

Cutter SL (ed) (2001) American hazardscapes: the regionalization of hazards and disasters. Joseph Henry Press, Washington, DC

Doswell CA, Moller AR, Brooks HE (1999) Storm spotting and public awareness since the first tornado forecasts of 1948. Weather Forecast 14:544-557

Duclos PJ, Ing RT (1989) Injuries and risk factors for injuries from the 29 May 1982 Tornado, Marion, Illinois. Int J Epidemiol 18:213-219

Eidson M, Lybarger JA, Parsons JE, MacCormack JN, Freeman JI (1990) Risk factors for tornado injuries. Int J Epidemiol 19:1051-1056

Galway JG (1981) Ten famous tornado outbreaks. Weatherwise June:100-109

Golden JH (1997) Tornadoes. In: Workshop on Social and Economic Impacts of Weather, Boulder, CO, April 2-4, 1997. NOAA/OAR/USWRP, Silver Springs, MD; available at http://sciencepolicy.colorado.edu/socasp/ weather1/golden.html

Golden JH (1999) Tornadoes. In: Pielke R Jr，Pielke R Sr (eds) Storms, Vol II. Routledge Hazards and Disasters Series. Routledge, London, p 103-132

Golden JH, Adams CR (2000) The tornado problem: forecast, warning, and response. Nat Hazards Rev 1:107-118

Grazulis TP (1993) Significant tornadoes 1691-1991. Environmental Films, St. Johnsbury, VT

Grazulis TP (2001) The tornado: nature's ultimate windstorm. University of Oklahoma Press, Norman

Hammer BO, Schmidlin TW (2000) Vehicle-occupant deaths caused by tornadoes in the United States, 1900-1998. Environ Hazards 2:105-118

Henson R, Horstmeyer S, Rippey B, Kocin P, Pinder E (1999) The 20th century's top ten U.S. weather and climate events. Weatherwise, Heldref Publications, Washington, DC. Abstract available at http://pqasb.pqarchiver.com/weatherwise

Lillibridge SR(1997) Tornadoes. In: Noji EK (ed), The public health consequences of disasters. Oxford University Press, New York, p 228-244

Editorial responsibility: Andrew Comrie,

Tucson, Arizona, USA
Mileti DS (1999) Disasters by design: a reassessment of natural hazards in the United States. Joseph Henry Press, Washington, DC

Mitchell JT, Thomas DSK (2001) Trends in disaster losses. In: Cutter SL (ed) American hazardscapes: the regionalization of hazards and disasters. Joseph Henry Press, Washington, DC, p 77-114

Monmonier M (1997) Cartographies of danger: mapping hazards in America. The University of Chicago Press, Chicago

Monmonier M (1999) Air apparent: how meteorologists learned to map, predict and dramatize weather. University of Chicago Press, Chicago

National Climate Data Center (NCDC) (2002) Billion dollar U.S. weather disasters since 1980. NCDC, Asheville, NC; available at http://www.ncdc.noaa.gov/ol/climate/severe weather/extremes.html

NOAA (1999) Weatherwatchers: NOAA releases century's top weather, water, and climate events. NOAA, Boulder, CO; available at http://www.weatherwatchers.org/education/century/nws.txt

Platt RH (1999) Disasters and democracy: the politics of extreme natural events. Island Press, Washington, DC

Riebsame WE, Diaz HF, Moses T, Price M (1986) The social burden of weather and climate hazards. Am Meteorol Soc 67:1378-1387

Schaefer JT, Kelly DL, Doswell CA III, Galway JG, Williams RJ, McNulty RP, Lemon LR, Lambert BD (1980) Tornadoes: when, where, how often. Weatherwise 33:52-59

Schaefer J T, Livingston R, Ostby FP, Leftwich PW (1993) The stability of climatological tornado data. In: Church C, Burgess D, Doswell C, Davies-Jones R (eds) The tornado: its structure, dynamics, prediction, and hazards. American Geophysical Union, Washington, DC, p 459-466

Sims JH, Baumann DD (1972) The tornado threat: coping styles of the North and South. Science 176:1386-1392

Sahr R (2001) Inflation conversion factors for years 1665 to estimated 2013. Oregon State University, Corvallis, OR; available at http://oregonstate.edu/Dept/pol_sci/fac/ sahr/derive03.pdf

Storm Prediction Center (2002) Tornadoes and deaths by year and month 1950-1999. NOAA, Boulder, CO; available at http://www.spc.noaa.gov/archive/tornadoes/ustdbmy.html

Thomas DSK (2001) Data, data everywhere, but can we really use them? In: Cutter SL (ed) American hazardscapes: the regionalization of hazards and disasters. Joseph Henry Press, Washington, DC, p 61-76

US Bureau of the Census (1997) Statistical abstract of the United States, 1997. Government Printing Office, Washington, DC

US Bureau of the Census (2001) USA statistics in brief. US Bureau of the Census, Washington, $\mathrm{DC}_{i}$ available at http://www.census.gov/statab/www/part1.html

White GF, Haas JE (1975) Assessment of research on natural hazards. MIT Press, Cambridge, MA

Submitted: October 1, 2001; Accepted: January 6, 2003

Proofs received from author(s): July 10, 2003 